\title{
Azerbaycan Dokumacılık Geleneği
}

\section{AZERBAIJAN CARPET-MAKING TRADITIONS}

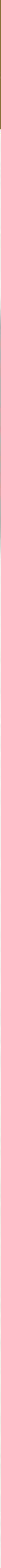

"Prof. Dr, Letif Kerimov adına Azerbaycan Halısı ve Halk Tatbigi Sanatı Devlet Müzesi

E-posta: tagiyeva_r@rambler.ru / mail@azcarpetmuseum.az 


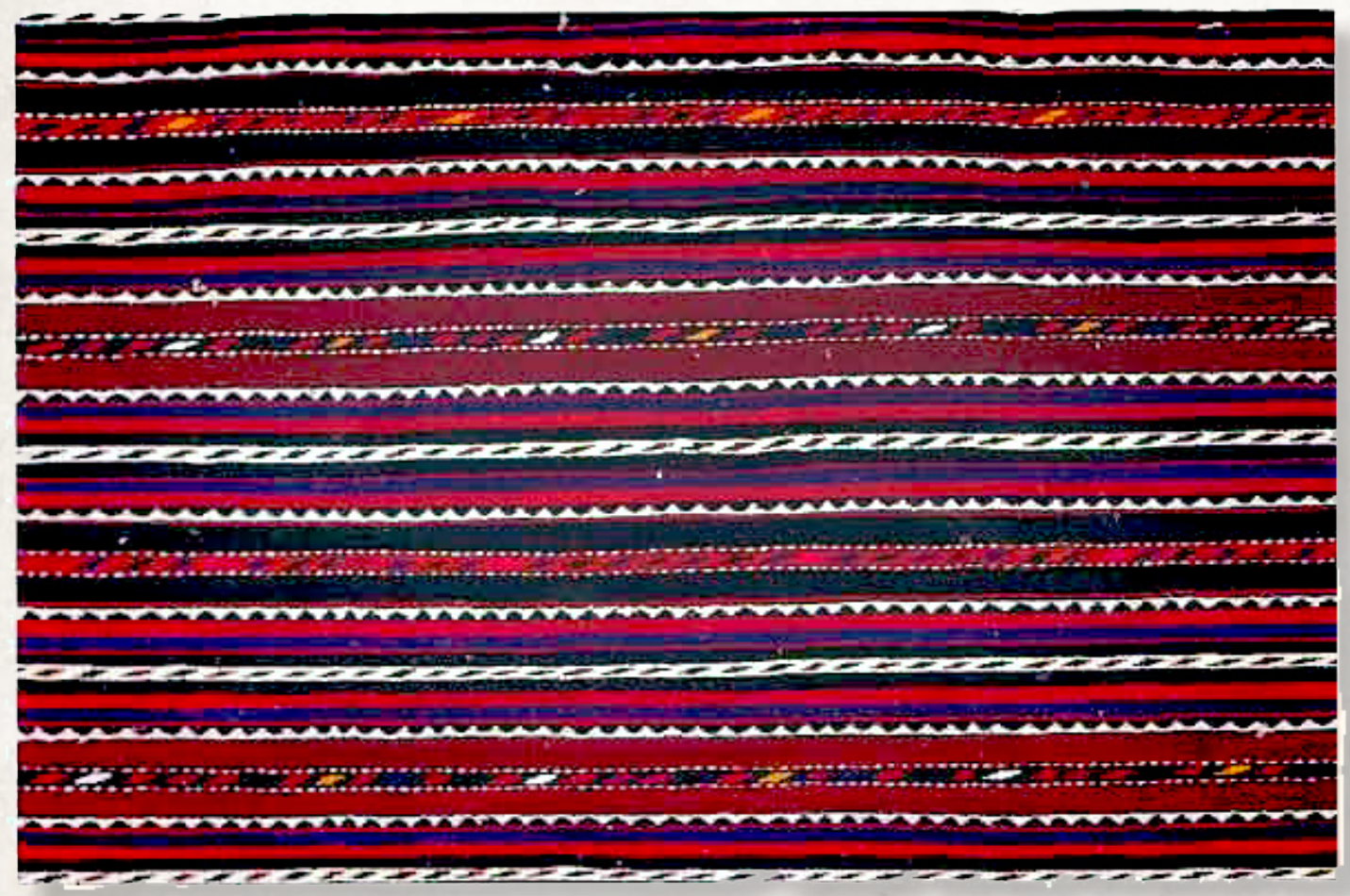

$\checkmark$ ünümüzde geçmişin manevi mirasının derinden oğrenilmesi, korunması ve herbir kesin bilinçaltı objesine dönüşmesi çok önemlidir. Azerbaycan'ın çağdaş cemiyetinin gelişiminde kültürel mirasın tetkiki, etnik kendine haslığın ifadesi ve belirlenmesi önemli hususlardandır.

Dokumalar kendilerinde halkımızın tarihi ve sosyal yönde geçtikleri uzun yolu yansitıyorlar. Tarihi-kültürel süreçlerin çeşitliliği kendini dokumaların karakterinde, dokuma tekniğinde, hazırlanma bölgesinde, üzerindeki desenlerde, elementlerde gösteriyor. Boşuna, halı tarihtir, geçmişle bağlı bilgileri bizlere ötüren kaynaktır denilmiyor.

Dokumaların aldığı isimler de hususi ilgi kaynağıdırlar: palas, cecim, zili, verni, kayık, gedceri, şedde, çul, sumak. Dokumalara verilen adlar özel olarak dokumacilar tarafindan düşünülürdü, fakat çoğu zaman tarihi, kültürel ve sosyal faktörlerin etkisiyle bu isimlerden bazıları değişebiliyordu.

Maalesef, hala Azerbaycan'da dokumaların taşıdıkları isimler araştırma konusu olarak yeterince ilgi çekmiyorlar. Bunun sonucu olarak da dokumaların taşıdıkları ilkin adlar göz önünde bulundurulmadan, incelenme zamanı aynı dokumalar farklı şekillerde adlandırılıyorlar ki, bu da onların doğru anlaşılmasına ve kabullenilmesine engel oluyor.

Bağımsız Azerbaycan'ın milli gelenekleri geliştirerek ve yaşatarak dünyevi entegrasyon sürecine katıldığı devirde bu konu daha da aktüeldir. Türk halklarının etno-kültürel dinamikliğinin gelişimi ile bağlı olarak bedii sürecin önemli unsuru olan bahsini ettiğimiz sorunun aktüelliği halkımızın etnik bilincinin yükselmesi ile daha da artiyor.

Dokuma adlarının incelenmesi onların tarihini bilmeye, gelişim sıralamasını belirlemeye, sembolün etno-şuurlu ve evrensel özgünlük arketipler ile alakasını yüze çıkarmaya ve nihayet bu dokumaların gelişim özelliklerini, geçmiş ve çağdaş durumunu yansıtan terminler sisteminin kurulmasına destek olacaktır.

Azerbaycan dokuma adlarında eski Türk kökenli daha derin tabakalar mevcuttur. Bunun dişında yalnız Türk etnomisi ve toponomisiyle bağlı adlar eski kabul ediliyor.

Mevcut durumdan çıkış yolu bulmak amacıyla dokumaların geleneksel terminolojisinin ilkin sisteminin tetkikinin berpası ve buna dayalı olarak Azerbaycan dokumalarının vasıflandirılması teklif ediliyor.
1. Palas. Bakı. Azerbaycan. XX y.y. Evveli. Şaxsi kolleksiyon. 
1. Palas: Azerbaycan düz dokuma yayg1ları arasında en geniş yayılan türdür (fotoğraf. 1). Palas neredeyse tüm geleneksel dokuma merkezlerinde üretilmiştir. Onun üretiminde ketan, kenef, kendir gibi bitkiden, yünden, pamuktan, deve yünü ve ipekten yapılmış iplikler kullanılmıştır. Palasın yapısını iki çeşitli iplik oluşturuyor: atkı ve çözgü. Sade veya koyu renkli çözgü iplerinin arasından çeşitli renklerde atkı iplerinin ensiz şeritler halinde geçirilmesinden oluşuyor. Onun üretim süreci desenin sade yöntemle esas kısımdan geçirilmesiyle oluşuyor. Dokumacilar palası tüm Azerbaycan'da makbul olan yatay çizgilerden oluşan geleneksel desenlerle süslüyorlardı. Fakat her bir dokumac1 eserinin renk özelliklerini ve kompozisyonunu belirlemekte özgürdü. Dokumacılar çizgilerin ölçülerini değişerek renk uyumlarını da değişiyor ve sonuçta palaslarin

2. Ciyi palas Bakı qrupu. Azerbaycan. XX Y.y. Evveli. Saxsi kolleksiyon. sayısız güzel örneklerini yaratıyorlardı. Palasın en önemli özelliği her iki yüzünün de kullanılabilir oluşu idi.

Günlük yaşamda hem çadırların kurulmasında, hem de yer yaygısı, örtü, giyim vs. gibi de kullanilan palaslar eski devirlerde ve orta yüzyıllarda yas ve düğün merasimlerinde geniş yer alıyorlardı. Hükümdar ve aile üyeleri- nin yas merasimlerinde şehir minareleri adeta palasa bürünürdü. Dini törenlerde genelde palas giyim gibi kullanılmıs ve genellikle Azerbaycan'da palas geymek geleneği mevcut olmuştur. Palas, Azerbaycan'ın her bir bölgesinde (Kuba, Şirvan, Muğan, Bakü, Karabağ, Gence, Kazah, Göyce, Borcalı, Güney Azerbaycan) dokunmuştur ve bu bölgelerde üretilen en eski örnekler I-II y.y.-a ait Mingecevir mezarlıklarında bulunmuştur. Bazı Arap kaynaklarında $\mathrm{X}$ y.y.-a ait Muğan'da dokunmuş palasların ününden söz ediliyor.

Bakü'ye ait Hocahesenli, Gobu, Güzdek ilçelerinde, Şirvan, Karabağ, Göyce ve Tebriz gibi bölgelerde ender palas örnekleri dokunuyordu. Hocahesenli ve Gobu ilçelerinde özel siparişle ince, zarif, yüksek kaliteli Çiyi palaslar1 dokunuyordu (Fotoğraf 2). Bu palaslar ölçülerine bağlı olarak değil, daha çok çekisine göre değerlendiriliyordu. Zamanında Çiyi palası "suzeni" - sofra gibi kullanabilmek için onun çizgilerinin üzerine ek desen ipliğinden işleme yöntemi-çitemeyle desen ilave ediliyordu. Daha sonraları desenlerin palaslara dokuma sırasında islenmesi onların esas vasfina dönüşmüştür. Fakat çiteme kelimesi bu palasların isminde kendini korumuştur ve anlaş1lır kadarıyla Çiyi palas-desenli palas demektir. Eski Türkçede “çi/yi”, "çi/kin” kelimesi işleme yöntemiyle desen vurma, işleme demektir. Günümüzde Azeri Türkçesinde dikme ve işleme anlamında kullanılan çiteme kelimesinin esasını da "çi"-kökü oluşturuyor. Çiyi palaslar ince ve zarif dokumalar oldukları için onlardan yer yaygisı olarak faydalanılmıyor, yalnız duvarda süs, perde, örtü, genç kızlara çehiz gibi kullaniliyordu.

Günlük yaşamda kullanılan birçok eşyalar palas dokunuşlu oluyorlardı. Göyçe'de yorgan-döşek takımı palas adlanıyordu. Çeşitli bölgelerimizde palas Hene, Kesa, Kilim olarak da biliniyorlardı.

2. Cecim: Havsiz dokuma nevlerinden biri de cecimlerdir (Fotoğraf 3-4). Cecimler genelde pamuk, yün özellikle de keci (yararsız kozalardan edinilen kaba ipek iplik) ve kaliteli ipekten hazırlanmış ipliklerden dokunu- 


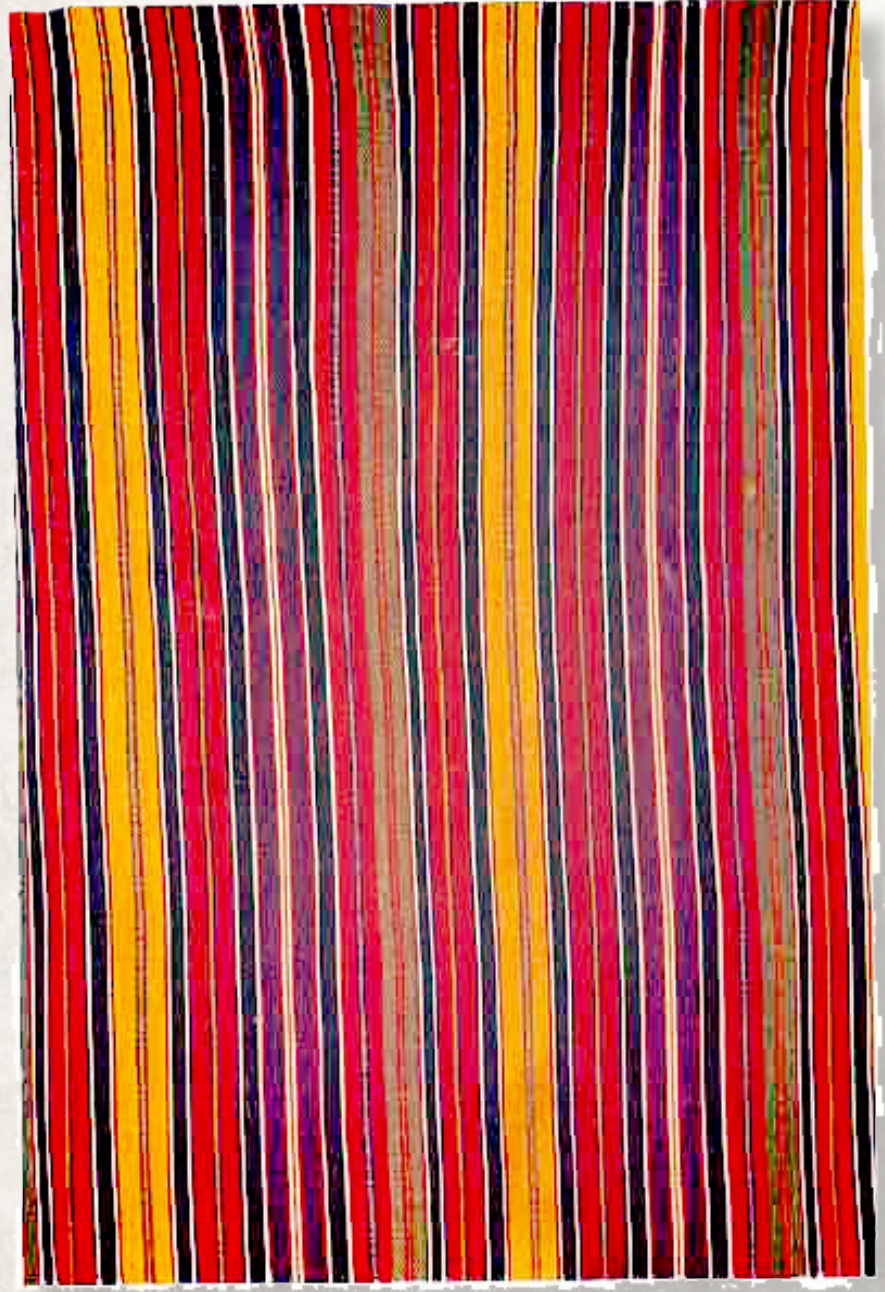

3. Cecim. Qarabağ. Azerbaycan. XX y.y. Evveli. Azerbaycan Halısı ve Halq Tatbiki Sanatı Devlet Muzesi.

luyordu. Bazen pamuk veya pamukla yünün karışımından hazırlanmış cecimlerle de karşılaşmak mümkündür. Cecimin yapısını iki farklı sistemli iplik oluşturuyor: atkı ve çözgü. Çözgüleri renkli (beyaz, kırmızı, sarı, koyu bej vs.) ipliklerden geriliyor ve bunların arasından geçirme tekniği ile tekrenkli atkı iplikleri tekbir-çapraz geçiriliyor. Çözgü ve atkının sıklığ1 eşit olmuyor, genelde çözgü iplikleri çok sıkı gerilir, boyanmamış atkı iplikleri bir alt bir üst sıkıca geçirilerek çözgülerin arasında saklanıyor ki, böylece çözgü yüzlü "cecim” oluşuyordu. Atkı iplikleri çözgü iplikleriyle nispette kalın olduğu için cecimin yüz kısmı kabarık oluyordu. Bu tarz dokumalar genelde yatay yer tezgahında yapiliyordu. Cecimin eni 25-30 cm.-i geçmezken uzunluğu $15 \mathrm{~m}$. ve daha fazla olabiliyordu. Böylece ensiz dokunmuş cecimlerden yapılacak ürünlerin (döşek, perde, geyim vs.) ölçüsüne uygun olarak kısımlara bölünerek kesiliyor ve biribirine dikiliyorlardı. Cecimler de palaslarda olduğu gibi çizgilerle susleniliyorlard1, fakat bu çizgiler palaslardakinden farklı olarak dikey yönde oluyorlardı. Bu çizgilerin yapısına göre cecimler sade ve mürekkep oluyorlardı. Nahcevan'lı dokumacilar bu çizgileri "tel”, onların aralarındaki tomurcukları ise "nigar" adlandiriyorlar. Cecimin yününün rengi ve kalitesine bağlı olarak hamar, tek renkli ve çiçek desenli cecimler mevcuttur. Cecimlerin bezek yapısı çeşitli ve çok zengindir. Cecimleri süsleyen çeşitli dikey çizgiler farklı, efektif, parlak ve dekora- tifdirler. Çoğu hallerde dokumacılar çizgiler günlük geçim eşyaları (tarak, iplik, şamdan) ve geometrik elemanların üsluplaştırılmış tasvirleri ile süslüyorlardı. Yünden ve pamuktan dokunan cecimler yayg1 ve duvar halıları gibi günlük yaşamda geniş kullanılıyordu. Zamanında cecimden kadın ve erkek geyimleri, döşekyüzü, yükyüzü, çeşitli örtüler, çanta, hurcun, eğer yüzü vs. eşyalar yapılird.

Azerbaycan'
da cecimin başlica üretim merkezleri $\mathrm{Ka}^{-}$
4. Cecim

Qarabağ

Azerbaycan.

XX y.y. Evveli.

Azerbaycan

Halısı ve Halq

Tatbiki Sanatı

Devlet Muzesi. 
rabağ, Kazah, Nahcevan, Şeki ve Şirvandır. Bunun dışında Güney Azerbaycan'da da cecim dokuma merkezleri vardır. Şirvan'da cecimler genelde ipekten, Karabağ'da yünden, Göyce'de ise pamuktan dokunuyor. Dikey çizgiler üzerine yapılan desenler cecime iki yöntemle işleniyor: dokuma zamanı geçirme ve kayık tekniği ile veya dokuma bittikten sonra işleme usulü ile. Dokunma tekniği ve bedii özelliklerine göre cecimler iki kısma bölünüyorlar: alaköy ve hemyan cecimler.

5. Zili. Bakı. Azerbaycan.

$x X y . y$.

Azerbaycan Halısı ve Halq Tatbiki Sanatı Devlet Muzesi.

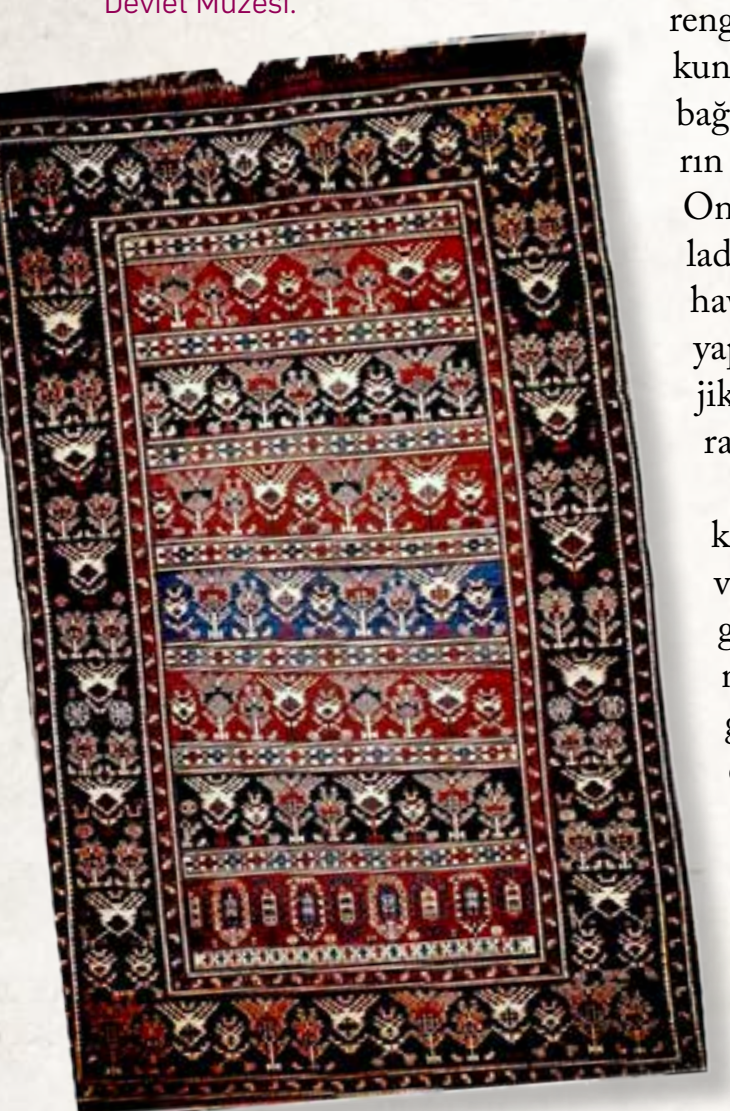

3. Zili: Havsız dokuma örneklerinden biri de zilidir (Fotoğraf 5, 6). Kompozisyon ve desen yapısına göre zililer çok çeşitlidirler. $\mathrm{Zi}^{-}$ liler yün, ipek ve pamuk ipliklerden dokunuyorlar. Zililerin dokunma tekniği, kullanımı, rengi, düzenlenmesi dokunduğu bölgeyle sıkı bağlıdır. Bu dokumaların sabit yapısı yoktur. Onun dokunmasinda ladı, şedde, verni gibi havsiz dokumaların yapisina has teknolojik prensiplerden yararlaniliyor.

Zililer ibadet dokumaları, perde, duvar ortıüsü, döşek gibi kullanılır.Günümüzde de zililer genelde camiler icin dokunuluyorlar. $\mathrm{Bu}$ tür zililer esasen lacivert - beyaz veya kırmızi-beyaz renkte oluyor, bordürlerinde de Namazlik dokumalara has arap kaynaklı dini yazılar yer alıyorlar.Başlıca zili üretim merkezleri Karabağ, Kazah, Bakü, Nahcevan, Göyçe ve Güney Azerbaycan'dır.

Zili tekniğine göre: karimış ferş, kullanımina göre: namazlık, bedii özelliklerine göre: damarlı ve zili kuşlu, zili şedde, hacı nağı zilisi, kalitesine göre fakir palası gibi nevlere bölünüyor. Zili Bakü 'de kayak-palas, Karabağ' dakayık, ladı, şedde, Kazah'da kayık, ladi, Tovuz'da derme, Güney Azerbaycan'da ladi, vernı, zilu vs. adlarla tanınıyor. Göyçe'de ise ziliye ölçülerine bağlı olarak halı, gebe ve büyük halı diyorlardi. Geneldeyse her türlü yer yaygisi hatta hasır bile çoğu zaman zili adlaniyordu.

4. Ladı: Yün ve pamuktan yapilan ipliklerden dokunan ladila-

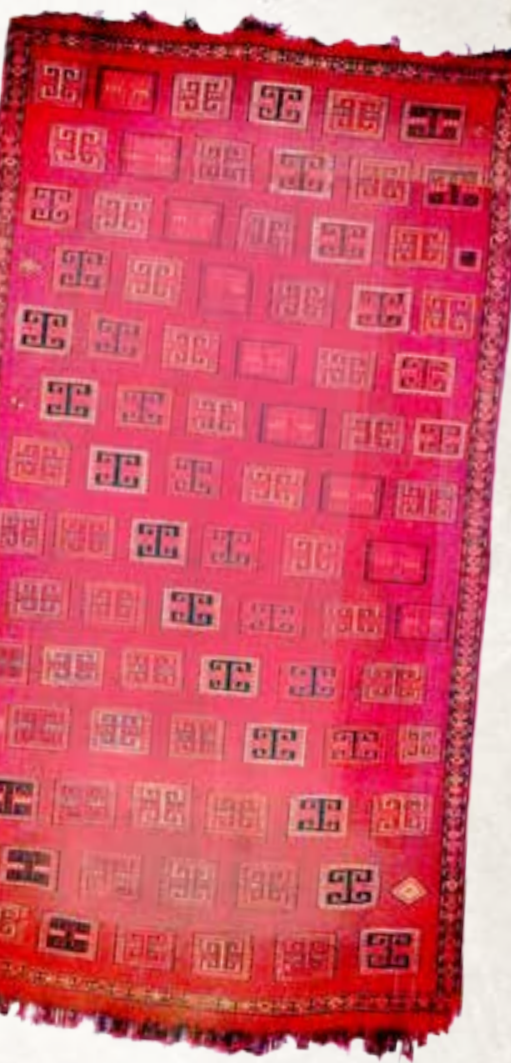

6. Zili. Qazax Azerbaycan. XX y.y. evveli. Azerbaycan Halısı ve Halq Tatbiki Sanatı Devlet Muzesi. rın dokunma yapısının esasını üç farklı iplik oluşturuyor: atkı, çözgü ve ek olarak desen ipliği. Ladılar geçirme tekniği ile, desen ipinin çözgü iplerinin arasından yatay yönde, çeşitli şekilde geçirilmesiyle dokunuyor ki, bu geçirmeler sonucu "sırıklar" oluşuyorlar. Bu tarz dokuma ladı tekniği adlaniyor (Fotoğraf 7). Bu tekniği palas tekniğinin bir şekli gibi kabul edebiliriz. Fakat bu dokumalarda atkı ipleri çözgü iplerinin arasından belirli say hesabıyla geçiriliyorlar. Bunun sonucu olarak da genişleyip daralan, fark11 ölçülü yatay desenli ürünler oluşuyor. Ladılar iki yöntem esasında dokunuyorlar: birinci yöntemde ladılar dikey tezgahta dokunuyor, yerliği tekrenkli, şal gibi hem çözgü, hem atkı yüzlü veya palas gibi yalnız atkı yüzlü olur, desen ipliği bir üst, iki alt çözgüye geçiriliyor ve oluşan narin, kabarık geçirmeler "sırıklar" şeklinde desenler oluşturuyorlar. İkinci yöntemle dokunan ladının yer tezgahında cecim 


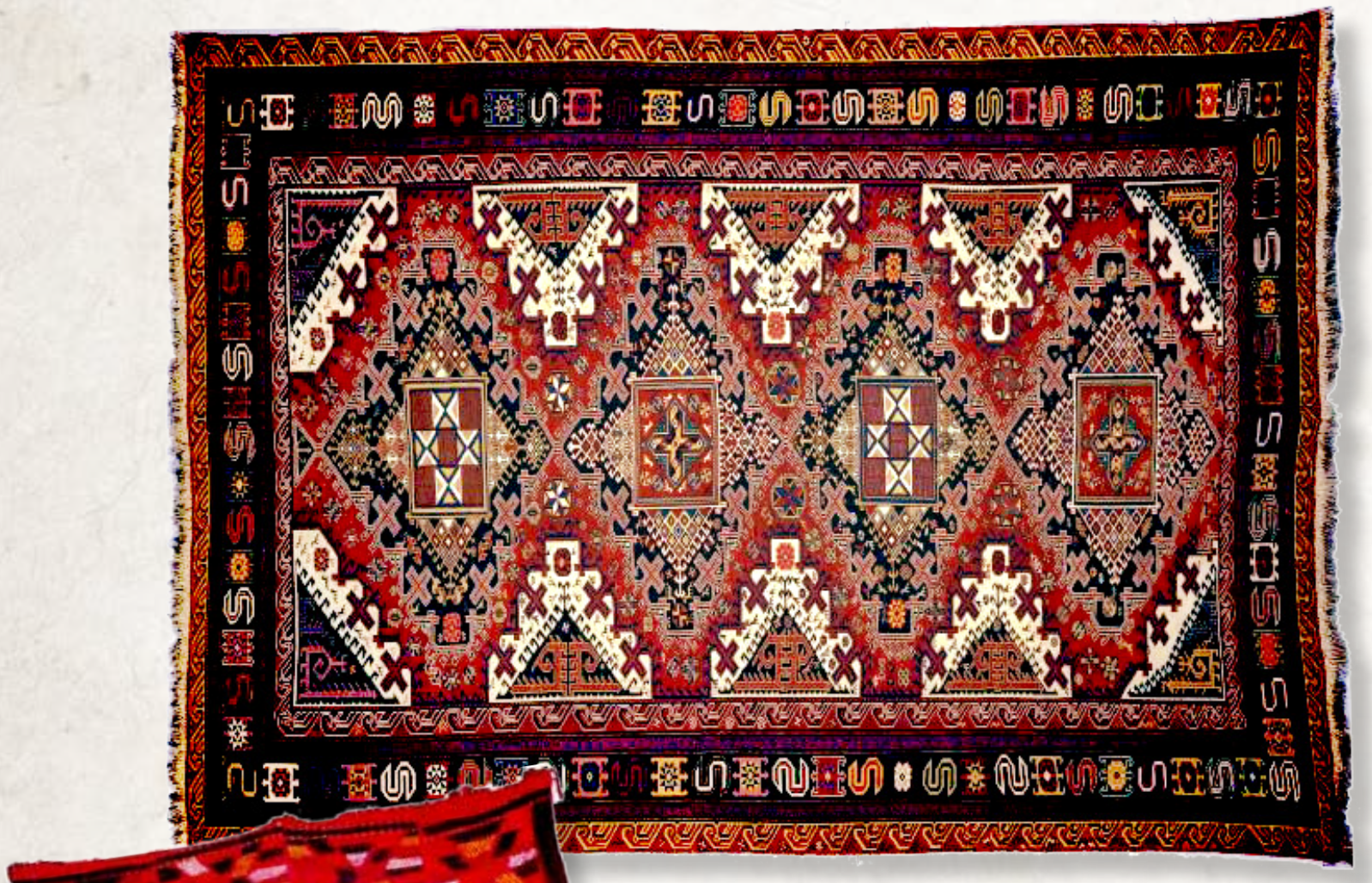

9. Sumax.

Şirvan.

Azerbaycan.

$X X$ y.y.

Azerbaycan

Halısı ve Halq

Tatbiki Sanatı

Devlet Muzesi.

gibi kısımlarla, ensiz, çözgüleri renkli, fakat cecimden farklı olarak tek renk geriliyor ve atkılar ayni renkde dokunuyorlar. Sonuçta yerliği tek renkli ve cecim gibi çözgü yüzlü oluyorlar. Ladı günlük yaşamda döşek, duvar örtüsü vs. gibi kullanılıyordu. Ladılar Azerbaycan'ın Karabağ, Kazah, Tovuz, Yardımlı bölgelerinde ve Güney Azerbaycan'da dokunuyorlar. Günümüzde ladı tekniğinde çalışan dokumacıların çoğu Azerbaycan'ın Yardımlı, Astara ve Lerik bölgelerinin dağ köylerine ait kişilerdirler. Ladı havsız dokumalarına Kazah ve Karabağ'da zili, Göyçe, Kazah ve Karabağ'da derme, Kazah, Göyçe, Borcalı' da derme kilim, Lenkeran'da geçirme palas deniliyor.

Ladı aynı zamanda havsız dokuma ürünlerinde sık kullanılan tekniktir. Bu teknik yöntemle diğer dokumalara: palaslara, lad1-cecimlere, şeddelere desen işleniyor. Yünden bazen de ipekten dokunan Sumak havsız dokumalarının ilmekleri bir kaç yöntemle yapilıyor (Fotoğraf 8, 9). Kayık tekniğinin iki usulünden çeşitli versiyonlarda, "sarma dolama" veya "halkalı dolama" usulüyle, bazense bir sıra soldan sağa" sarma dolama", diğer sıra ise soldan sağa "halkalı dolama" şeklinde dokunuyor. İlmeklerin yüzü bir sırada yukar1ya, ikinci sırada aşağıya doğru yön alıyor ki, bu da buğday tanelerinin sünbülde sıralanmasinı 
Üzerine bitki, hayvan ve insan tasvirlerinin hendesileştirilmiş figürleri işleniliyor. Kilimler dokundukları bölgelere bağlı olarak kompozisyon, renk ve desenlerine göre farklanıyorlar. Günlük yaşamda sık yer alan kilimler yer yaygısı, duvar örtüsü, kap1 yerine örtü gibi, perde, sofra vs. gibi kullanılmış, onlarla deve ve katırlar süslenilmiştir. Başl1ca üretim merkezleri Bakü, Kazah, Karabağ, Şirvan ve Tebriz'dir. Kilimin önemli özelliklerinden biri de her iki yüzünün kullanılabilir oluşudur. Çok ender hallerde tek yüzlü dokunuyorlar. Kullanılan materyale göre kilimler: kendir kilim, kenef kilim; tekniğine göre: tırnaksız kilim, gezmeli kilim, karvud, tahta kilim, kullanım alanına göre bucak kilimi, dal kilimi, çadır örtüğü vs., bedii özelliklerine göre: haşiyeli kilim, küçük göllü kilim, küçük desenli kilim vs. gibi türleri vardır.

Kilim kelimesinin orta asırlarda Türk halkları arasında yaygın olan "kerim" kelimesinin tahrif olunmuş şekli olduğu varsayımı mevcuttur.

7. Verni: Daha bir havs1z dokuma türü verni adlanıyor (Fotoğraf 12). Bu dokumalar genelde yünden, ender hallerde ise ipek ve pamuk iplikten yapil1yor. Verninin yapısını üç farklı iplik; çözgü, atkı ve ek olarak desen ipliği oluşturuyor. Her bir ilmek siralamasindan sonra alt veya üst atkı "doyumlu" geçiriliyor. İlmekler tüm sıralamalarda soldan sağa, yanyana salınarak paralel, tekyönlü dizgi oluşturuyor ki, bu da verninin yüz kısmını tamamile kapatıyor. Sonuç olarak verninin yüz kısmını "desen ipliği” oluşturuyor. "Desen ipleri” nin uçları arka yüze çıkarılmıyor, atkılarin arasında kayboluyor.

Verniler iki kısımdan oluşuyor: sağ ve sol.
Daha sonra bu kısımlar biribirine dikiliyorlar. Bu nedenle Karabağ'da (Lemberan) bu dokumalar hemyan (çift taraflı) adlandırılıyorlar. Lenkeran'da verniye kayıklı kilim deniliyor. Verniler perde, yük örtüsü, döşek, örtü cadırlara dekoratif süs gibi kullanılıyordu. Muğan'da döşek gibi kullanılacak vernilerin arka yüzüne keçe dikiliyordu.

Vernilerin esas üretim merkezleri Karabağ (Berde, Susa, Ağcabedi, Cebrayıl, Lemberan), Kazah, Nahcevan ve Güney Azerbaycan'dır. Karabağ vernisinin süslemesinin esas elemanı neredeyse dokumanın tüm sahasını kapsayan "S" veya " $Z$ " şekilli stilize edilmiş ejderha tasviridir. Ejderha bereket sembolü ve

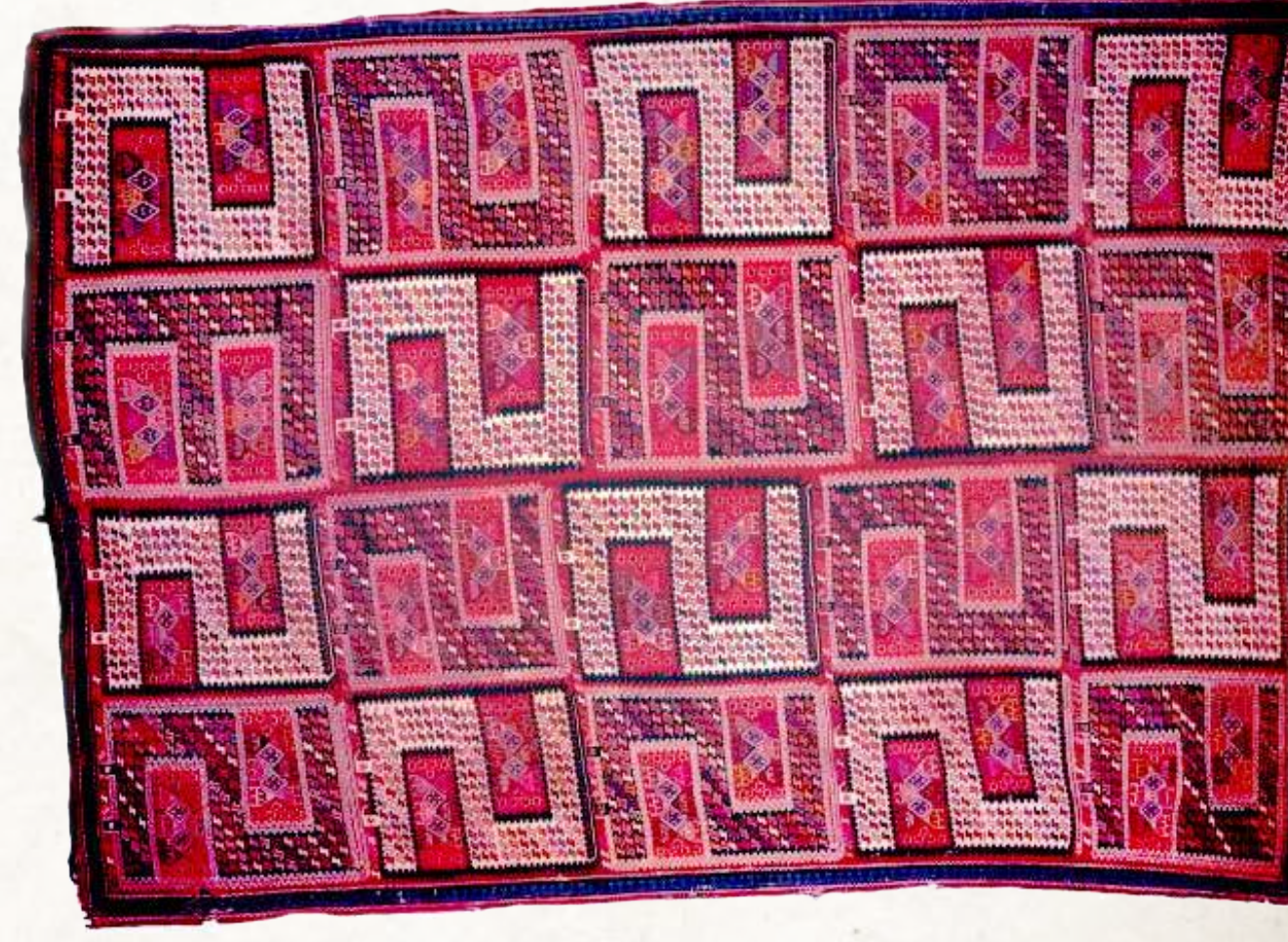

12. Verni. Qarabağ. Azerbaycan. XX y.y. Azerbaycan Halısı ve Halq Tatbiki Sanatı Devlet Muzesi.

evin, kabilenin koruyucusu gibi biliniyordu. Ayni zamanda ejderha eski devirlerde kötü güçlerin de sembolü gibi tanınmıştır. Güney Azerbaycan'da dokunan verniler genellikle kuş ve ağaç tasvirleriyle süsleniyorlar. Orta asırlarda zarif dokunuşlu verniler bernu, perniyan, pernu da adlanıordu. Bu tarz dokumaların birkaç nevi vardı ve onlar esasen döşek gibi kullaniliyordu. 


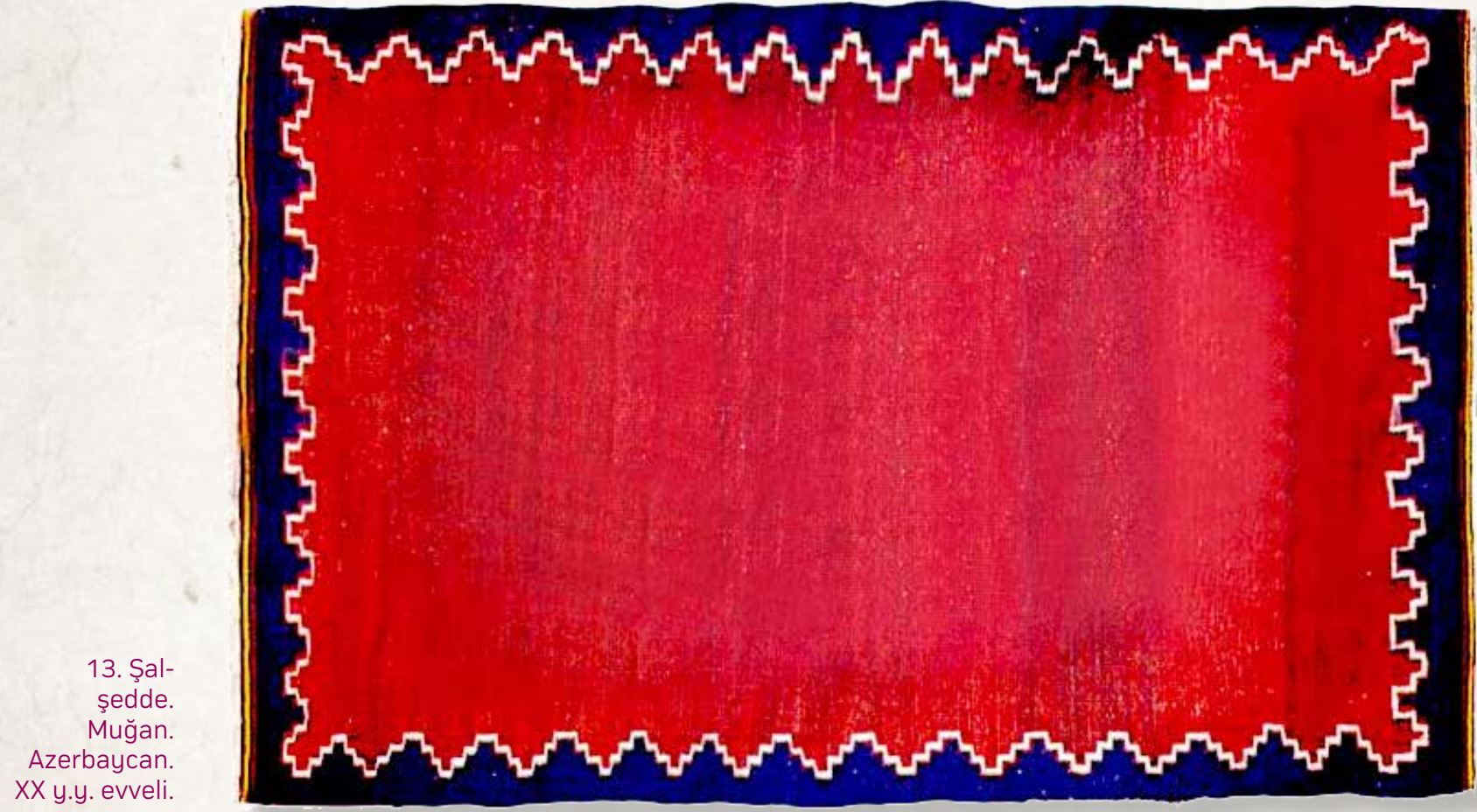

14. Damadama Sedde. Gazah. Azerbaycan $X X . y . y$.

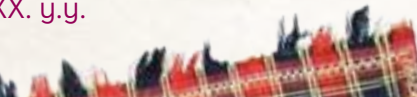
(4) 5 $12+\frac{3}{3}$ 15
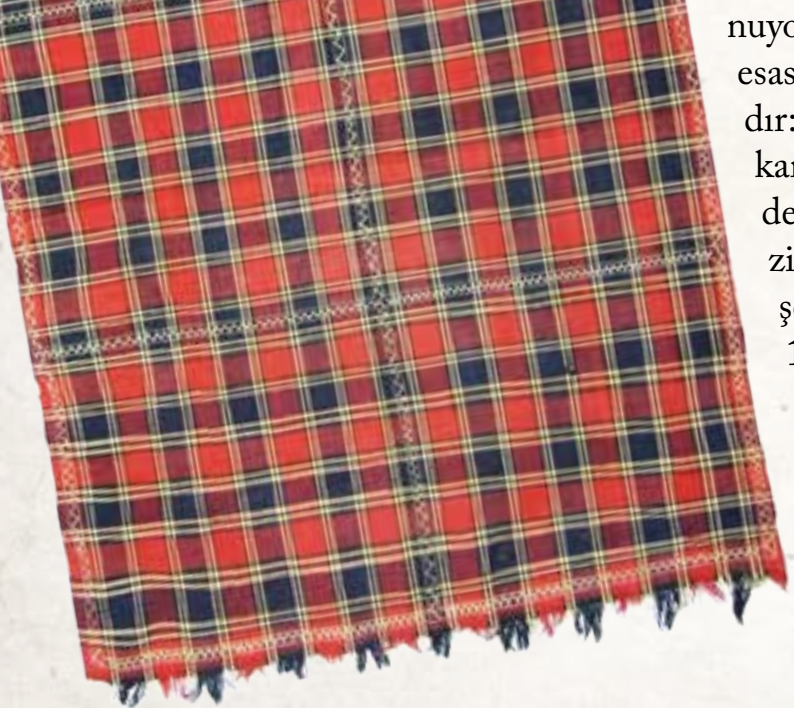

Havsız dokuma türlerinden olan şedde yün, pamuk ve ipek ipliklerden dokunuyor. Şeddenin yapısı- nı iki tür iplik oluşturuyor: çözgü ve atkı. Genelde şeddeler biribiriyle birleştirilmiş kırmızı veya kırmız1- lacivert renkli kısımlardan oluşuyor. Bununla beraber tek kısımlı kırmızı şeddeler, kırmızı, lacivert renkli dikey çizgili şeddeler de dokunuyordu. Şeddelerin esasen üç türü vardır: tekrenkli-şal; kareli-damalı şedde ve mezmunlu zili şedde, develi şedde (Fotoğraf $13,14,15,16)$. Günlük yaşamda şeddeden tören perde ve örtüleri gibi (çile şeddesi) faydalan $1 l_{1-}$ yordu. Zamanla kalın dokunuşlu şeddelerden döşek, duvar örtüsü; zarif ve ince dokunuşlu şeddelerden ise kadın ve erkek giyimleri, sofra hazırlanıyordu. Küçük kırmızı şeddelerse ayakaltllğ̆ gibi kullanılıyordu. Önemli şedde üretim merkezleri Karabağ (Kubatlı, Cebrayıl, Ağdam, Berde), Kazah, Nahcevan, Güney Azerbaycan (Erdebil, Meskin, Muğan) ve Göyçe'dir. Tekniğine göre: gedirge, şal, şedde cecim, kullanımına göre: çille şeddesi, bey çadırı, godu parçası, şedde kilim, bedii özelliklerine göre: develi şedde, kare şedde vs. adlandırilıyordu. Bakü'de şedde kayak-palas, Karabağ'da zili, Nahcevan'da cecim, Güney Azerbaycan'da bucakkırağı, ocakkırağı (bucak kenarı, ocak kenarı) adlarıyla biliniyordu. Muğan bölgesinde pamuk iplikten dokunan palas ve küçük ölçülü palas şedde adlanılıyordu. Şedde kelimesinin kaynağını "Şetrenc", "Sadeverd" yani satranç kelimesinden aldığ ihtimal ediliyor.

Nahcevan'da (Şahbuz) yer tezgahında dokunan zarif cecim, şedde-cecim adlanıyor. Şedde kilim ise gerdeklik kırmızı kilime verilen addır. VI-VII y.y.larda Güney Azerbaycan'da dokunan kaba palaslar Şeleng adlanıyorlardı. Değerli halıları rutubetden korumak amacıyla 


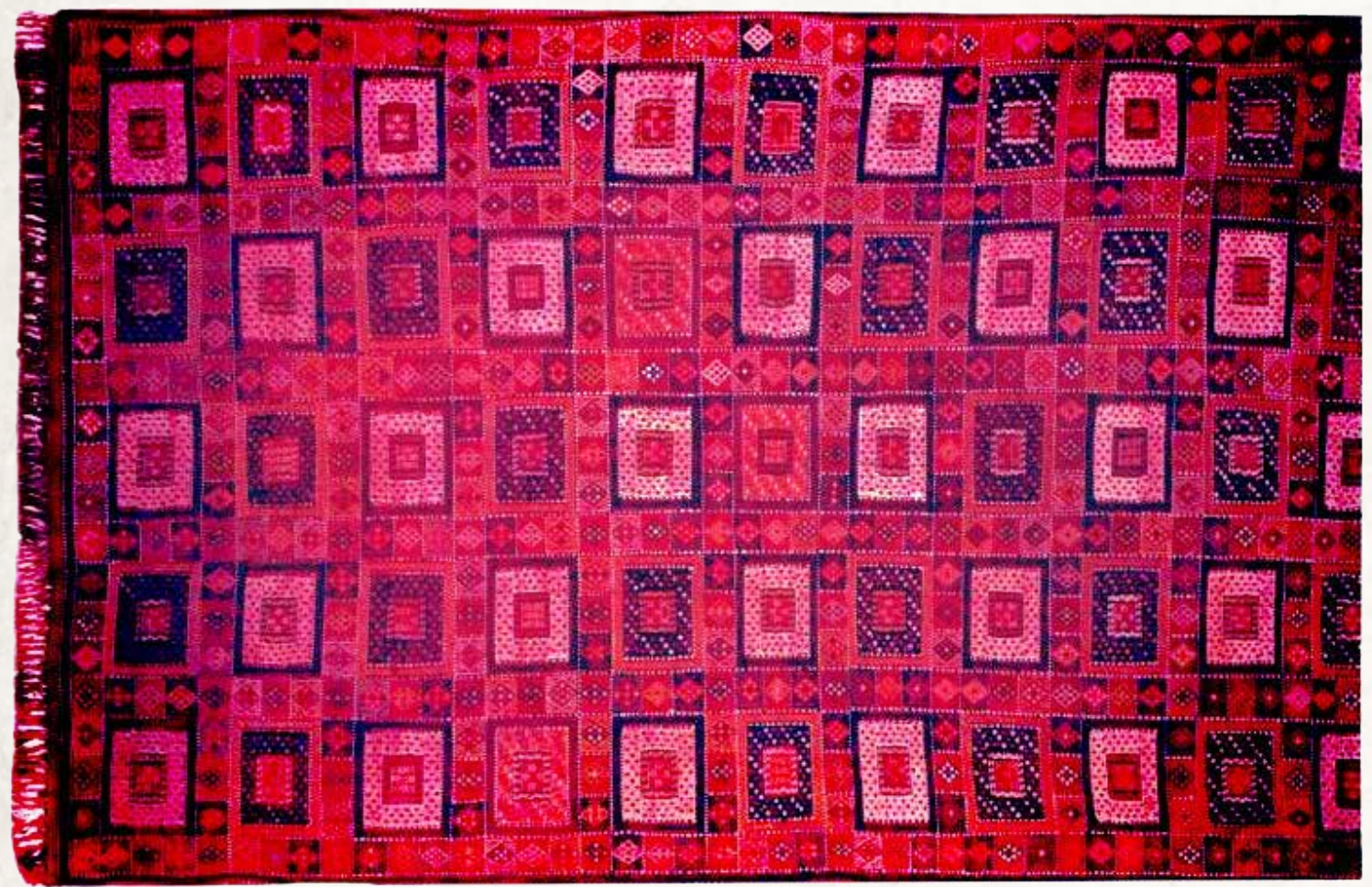

15. Şedde. Qarabağ. Azerbaycan. XX. y.y. evveli.

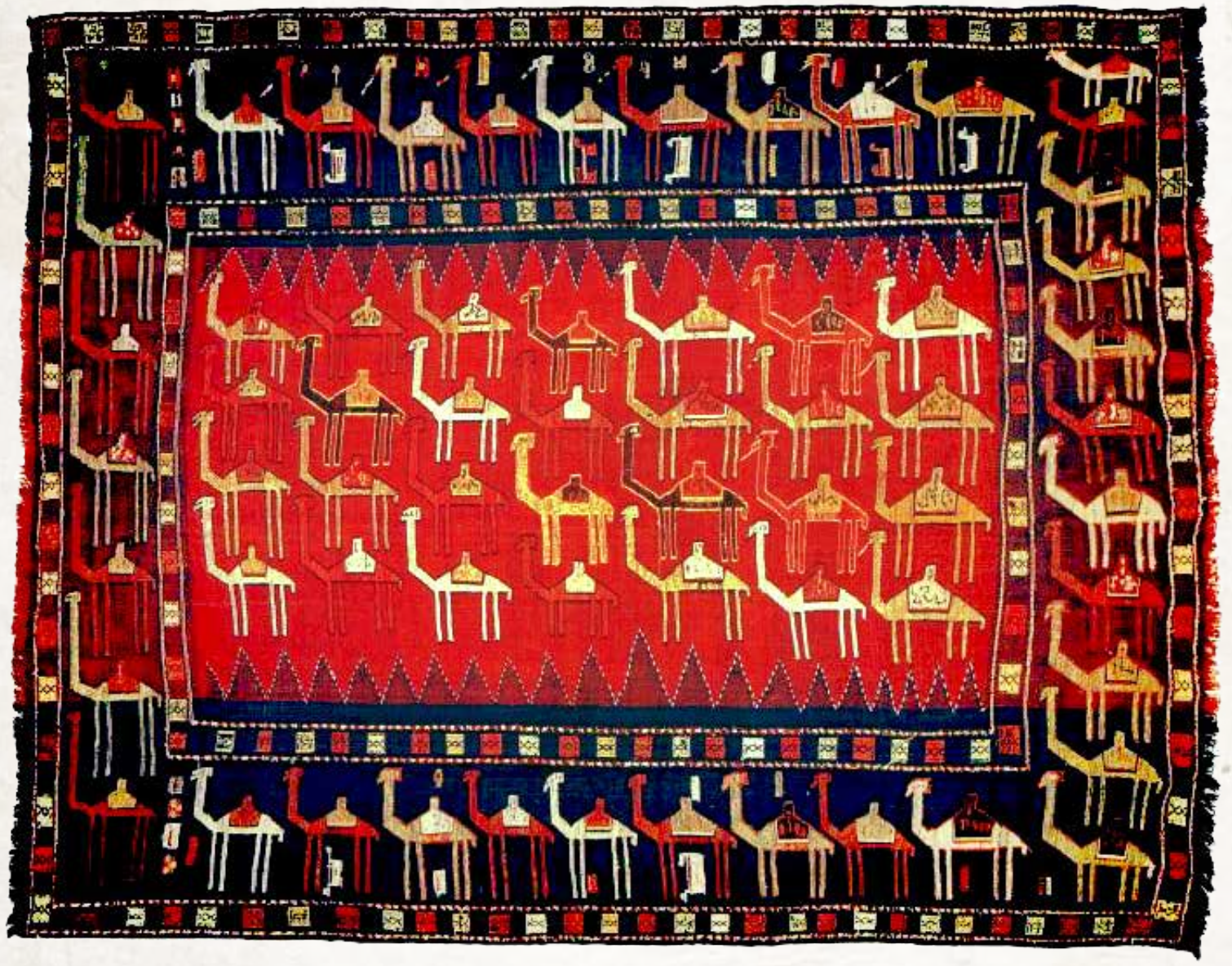

16. Şedde. Qarabağ. Azerbaycan. XX. y.y. evveli. 


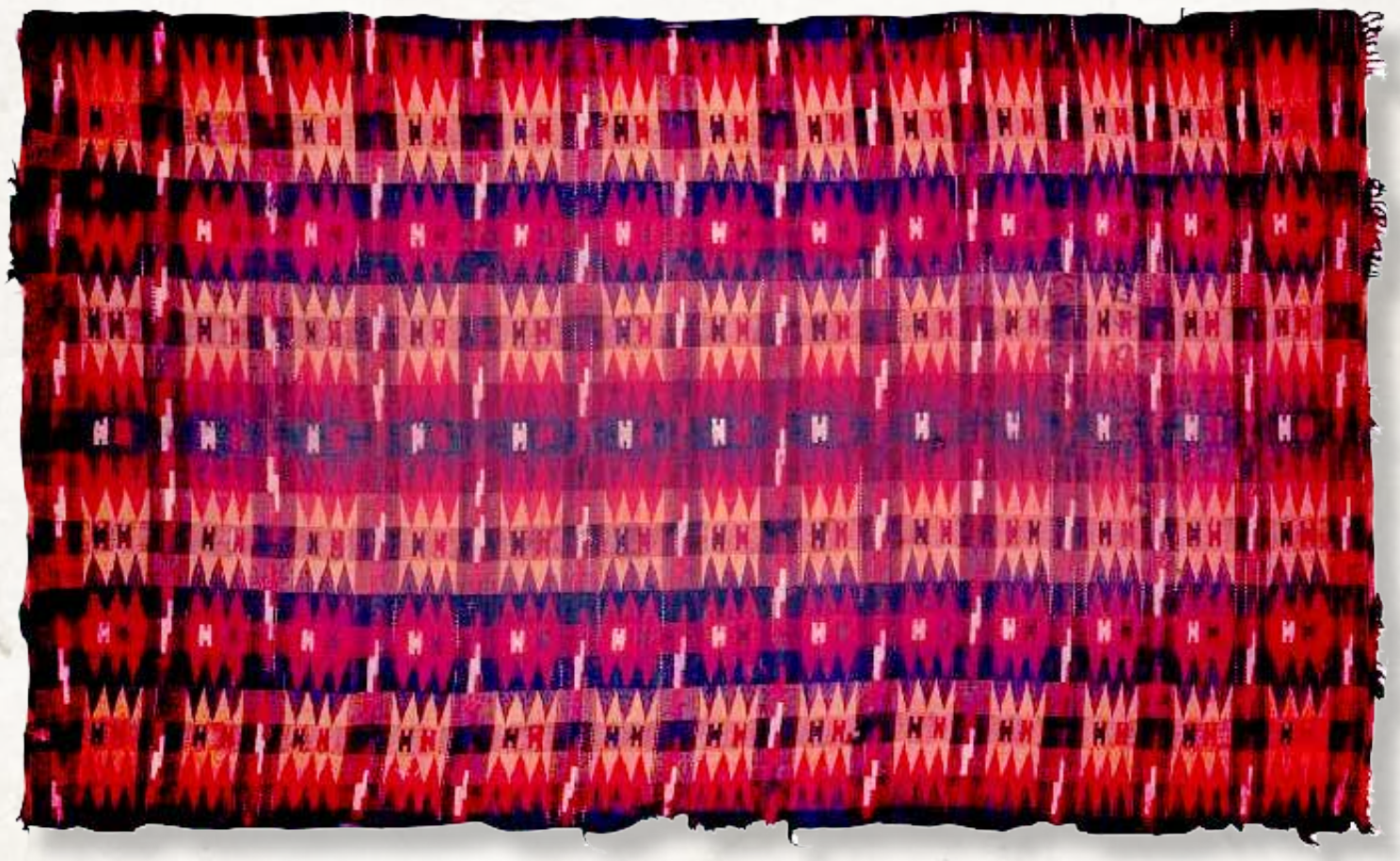

17. Gedirgen Şedde. Şirvan Azerbaycan. XX y.y. evveli.

onların arka kısmına genelde şeleng dikiliyordu. Orta asırlarda kareli (damadama) şeddeler setrenc adlanırdı ve yün veya ipekten dokunuyorlardi.

Dikey enli, dalgalı çizgili şeddeler gedirge adlaniyorlardı (fotoğraf.17). Bu tarz desenler "okbaşı" veya "taraklı" gibi biliniyorlar. Gedirgeler yüksek kaliteli yün ve pamuktan yapıl1yor. Onun yapısını iki tür iplik çözgü ve atkı oluşturuyor. Geçirme tekniği ile atkı ipliği çözgülerin arasından teker ve capraz olarak geçiriliyor. Çözgü ve atkı aynı sıklıkta oluyor, alt ve üst atkılar doyumlu geçiriliyor ve yüz kısmı şeddede olduğu gibi çözgü ve atkı yüzlü oluyor. Gedirgenin desenleri renkli çözgü ve atkı ipleri (kırmızı ile lacivert, siyah ile gri, kırmızı ile beyaz, lacivert vs.) vasitasıyla, kilim tekniği ile yapılıyor. Bu zaman gedirgenin üzerinde çok küçük "tırnakları" (delikleri) oluyor ki, dokumanın aldığı ismin bununla alakalı olduğu düşünülüyor. Gedirge "delik" demektir. Genelde onu yer yaygisı gibi kullanıyorlardı. Çadırların üzerine serilen bu dokumalar Karabağ'da "Peykam” gibi biliniyorlard1. Karabağ'da (Kelbecer) gedirge taraklama, Abşeron'da taraklı palas, Abşeron'un bazı köylerinde "Misar" adlanıyor. Şedde havsız dokumalarına tasvir işlemek için kayık tekniği kullanılıyordu. Bu nedenle de bazı bölgelerde hususen Abşeron'da (Hızı) şeddeye kayık-palas, Güney Azerbaycan'da ise "kayık dokunuşlu halı" denilir.

Dama-dama şeddelerin başlıca süs elemanı karelerdir. Siyah-beyaz kareli bu tarz şeddeleri mürşid (sufi rehberi) oturan tahta seriliyor veya yatağının üzerinden asıyorlardı. Günlük yaşamda onlardan bayram ve düğün kıyafetleri, çadra, perde, yatak takımları yapilıyordu. Canlı ve kırmızı kareli şeddeler damat çadırlarının yapılışında da kullanılırdı. Kullanım alanına göre bu şeddeler çille şeddesi ve ön sofrası gibi nevleri vardır. Karabağ ve Kazah'ta zarif, sakin renkli kareli şeddelerin damaları ladı, kayık tekniği ile stilize edilmiş hayvan ve kuş tasvirleri ile süsleniyordu. Kareli şeddeler bucakkırağ1 (bucak kenarı), kesmeli şedde, ocakgırağı da adlanıyordu. Orta asırlarda onlar şetrenci de adlanmıştırlar.

Hayatın tüm alanlarını etkileyen kültürümüzün, sanatımızın canlı tarihi salnamesi olan dokumalarımız muazzamlığı ile dünya kültürel toplumunun hep ilgisini çekmiştir. 
Dünya müzelerini süsleyen dokumalarımız milletimizi yurtdışında yüksek düzeyde tanıtıyor. Bizler halılar üzerinde ilk adımlarımızı atıyor, hayatımıza onlarla renk katıyor, evimi$\mathrm{zi}$, ailemizi onunla 1sitiyor ibadetimizi onun üzerinde yapiyor ve nihayet ahiret evine onun üzerinde göçüyoruz. Halılar o kadar saf ve temizler ki, kutsal kitabımız Kuran da "Onlar (ehl-i cennet) yastıklara ve güzel desenli halılara dayanmış olacaklar.” Aynı zamanda dokumalardan tedavi amaciyla da faydalanıliyordu.

\section{KAYNAKLAR}

Letif Kerimov (1961). Azerbaycan Halısı, I.cild, Leninqrad.

Letif Kerimov (1983). Azerbaycan Halısı, II. cild, Bakü.

Letif Kerimov (1983). Azerbaycan Halısı, III. cild, Bakü.

Röya Tagiyeva (1999). Azerbaycan Halısı, İstanbul.

Röya Tagiyeva (2006 ). Azerbaycan Halısı Meişetde, Azerbaycan, Bakü. 